\title{
Investigations of Exterior Wind Flow and Aerodynamic Coefficient around Y-Plan Shape Tall Building
}

\author{
Vigneshwaran RAJENDRAN ${ }^{1}$ \\ Prabavathy SHANMUGASUNDARAM ${ }^{2}$
}

\begin{abstract}
In recent years, the construction of skyscrapers is emerging in many countries and the study on the behaviour of wind around the building receives an additional interest among structural engineers and architects. Mostly, tall skyscrapers are planned in the shape of ' $Y$ ' in order to have a maximum exterior view and to support the central core of the structure. In the current scenario, it is important to study the actual wind load for irregular plan shape building. This paper presents the numerical wind flow simulation around ' $\mathrm{Y}$ ' plan shape tall building using ANSYS Fluent software and validation is done using wind tunnel testing. The building model and wind velocity are scaled to the ratio 1:300 and 1:5 respectively. A wind velocity of 10 $\mathrm{m} / \mathrm{s}$ is applied both for wind tunnel testing and for the numerical simulation. Error analysis is carried out in order to check the accuracy of the results obtained between wind tunnel and CFD. From the test results the mean $C_{p}$ is investigated for various faces of the building for the wind angle $0^{\circ}, 45^{\circ}$ and $90^{\circ}$ from both using CFD and wind tunnel. The investigation of drag and lift coefficient is made on Y-plan shape building and it is observed that the maximum drag occurs at $45^{\circ}$ wind angle, because of the less projected area when compared with the other wind angles $0^{\circ}$ and $90^{\circ}$ respectively. Further, this paper continues with the physics of wind flow behaviour around Y-plan shape building and flow character such as vortex formation, streamlines and identification of wake region for different wind angles.
\end{abstract}

Keywords: Aerodynamic forces, Computational Fluid Dynamics (CFD), wind tunnel, tall buildings.

\section{INTRODUCTION}

Today, $55 \%$ of the world population are living in cities and the percentage might increase in the upcoming years due to the availability of opportunities in cities. The rise in the urban population leads to the demand for land area and vertical constructions are increasing. These

\section{Note:}

- This paper has been received on March 6,2020 and accepted for publication by the Editorial Board on December 11, 2020.

- Discussions on this paper will be accepted by September 30, 2022.

- https://doi.org/10.18400/tekderg.699861

1 Department of Civil Engineering, Mepco Schlenk Engineering College, Sivakasi, India vignesh.rajen.93@gmail.com - https://orcid.org/0000-0003-2405-3898

2 Department of Civil Engineering, Mepco Schlenk Engineering College, Sivakasi, India spraba@mepcoeng.ac.in - https://orcid.org/0000-0001-6110-5912 
high-rise structures are subject to predominate lateral forces, mainly the wind force. For the past two decades, many researchers explored the wind effect on tall buildings and their response. It is possible to study the wind effects on tall buildings with both numerical and experimental methods. The following earlier researchers Yasushi Uematsu et al and G.M. Richardson et al [1,2] adopted the wind tunnel tests to investigate the dynamic behaviour wind loads on engineering structures such as single-layer latticed dome, siloes structures using wind tunnel tests. In this regard, the investigation of aerodynamic coefficient such as drag and lift coefficient for a rectangular tall building with $0^{\circ}$ and $90^{\circ}$ wind angles are investigated by the author Chitra ganapathi et al [3]. The test is carried out for different terrain conditions namely suburban, open, and uniform terrain conditions. From the results, it is well known that the terrain condition has a greater influence in the pressure coefficient $\left(C_{p}\right)$ at different faces of the building.

In addition to the experimental studies and with the recent development of supercomputer and turbulence model in $20^{\text {th }}$ century makes it possible to predict the wind flow behaviour around the tall buildings and to have a comparative study on wind pressure distribution around the building with both numerical and experimental methods. The numerical prediction of wind flow around a rectangular plan shape building is done successfully by Ben Mou et al [4] using RNG k- $\varepsilon$ turbulent model and the distribution of the pressure around the building is investigated. The obtained result is compared with the Commonwealth Advisory Aeronautical Research Council (CAARC) standard models. The simulation of atmospheric boundary conditions is very much important for the wind flow around the building. Gu M and Quan Y [5] investigated the cross-wind load for fifteen typical tall buildings with different aspect ratios. The test is conducted in a high-frequency force balancing test. New formula for crosswind power spectra is investigated and compared with the previous result. Zhao Liu et al [6] performed a twisted wind flow on a square mega tall building using wind tunnel test and the results of pressure distribution are studied. In order to reduce the wind load on structure, many major and minor modifications are made on buildings with different shapes and is performed by the researcher Ashutosh Sharma et al and Kim Y., Kanda J [7, 8]. Further, the researchers continued with the detailed review of shape modifications in buildings such as curve corners and major modifications such as altering the building shape and elevation. These modifications lead to a decrease in wind loads by 30 to $60 \%$ and the wind flow pattern changes with the building shape and height. Further investigation is done on 'E' plan shape building by the author Biswarup Bhattacharyya and Sujit Kumar Dalui [9] using Wind tunnel and validated using Computational Fluid Dynamics (CFD) software for wind angles $0^{\circ}, 30^{\circ}, 60^{\circ}, 90^{\circ}, 120^{\circ}, 150^{\circ}$ and $180^{\circ}$. The scaling of building models is done using a 1:300 ratio. Rajdip Paul and Sujit Kumar Dalui [10] performed a wind pressure distribution around ' $Z$ ' plan shape building for wind angles $0^{\circ}, 30^{\circ}, 60^{\circ}, 90^{\circ}, 120^{\circ}$ and $150^{\circ}$.

The investigation of wind force and wind pressure acting on a tall building with unconventional configuration is carried out in the present study because most of the Wind Engineering (WE) codes are silent in providing the mean $\mathrm{C}_{\mathrm{p}}$ for irregular and complex geometry. Even in the revised code of Indian Wind Engineering Code (IWEC) IS875 (2015), there is a lack of mean $\mathrm{C}_{\mathrm{p}}$ for irregular plan shape building. Therefore, in the present scenario it is important to investigate wind flow around an irregular plan geometry using a wind tunnel testing and CFD analysis. 
This paper investigates the wind behaviour around Y-plan shape tall building. The reason for the selection of Y-plan shape building is that many existing tall skyscrapers such as Burj Khalifa of the height 828 meters and upcoming skyscrapers such as Kingdom/Jeddah Tower of height more than $1000 \mathrm{~m}$ are designed in the form of Y-plan shape. The investigation of Y-plan shape building is performed with both the wind tunnel testing and with the numerical simulation using CFD for the wind angles $0^{\circ}, 45^{\circ}, 90^{\circ}$ respectively. The test is performed for a constant wind velocity $10 \mathrm{~m} / \mathrm{s}$ and turbulence model realizable $\mathrm{k}-\varepsilon$ is used for the CFD simulation.

\section{EXPERIMENT SETUP}

The experiment is conducted using a subsonic wind tunnel, which is available in Kumaraguru College of Technology (KCT), Coimbatore, India. Figure 1 shows the schematic representation of a wind tunnel. The building models are tested in the wind tunnel of test section of size $0.6 \mathrm{~m} \times 0.6 \mathrm{~m}$ and the length of the tunnel is $40 \mathrm{~m}$. Figure 2 shows a pictorial representation of a test section of a subsonic wind tunnel. The experiment flow is simulated similar to terrain category - I as per IS 875 (Part-3) 2015. The value of ground roughness $Z_{0}$ as per code is 0.002 is used for both wind tunnel and CFD in this study. The building models scaled in the ratio of 1:300 and the wind tunnel is operated at a wind speed of $10 \mathrm{~m} / \mathrm{s}$. Since the blockage ratio lies between 9 to $11 \%$, necessary blockage correction is done for calculating the pressure coefficient $\left(\mathrm{C}_{\mathrm{p}}\right)$ from the building model. The power-law index $(\alpha)$ for the tunnel is 0.133 . The pressure measurements are taken with the help of a pressure tube which is connected to the manometers.

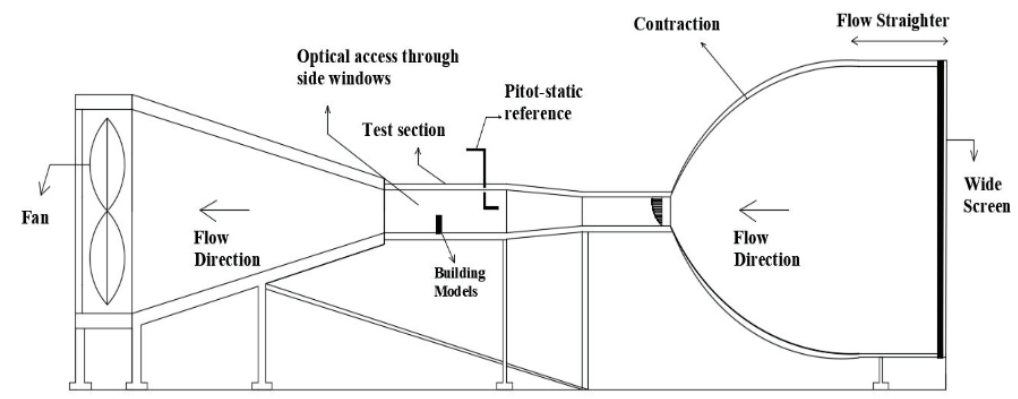

Figure 1 - Schematic representation of Wind Tunnel

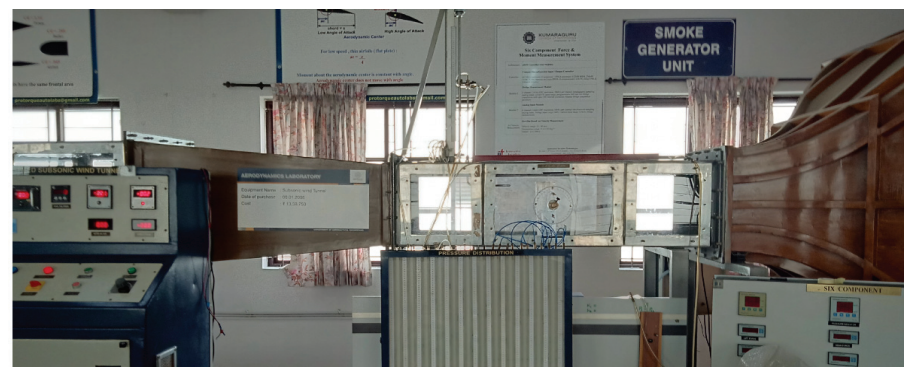

Figure 2 - Sub-sonic Wind tunnel test section 0.6 m $x 0.6$ m at Kumaraguru College of Technology $(K C T)$ - Coimbatore 


\subsection{Details of the Model}

The building models were made-up with the help of transparent perspex sheet (acrylic sheets) having a thickness of about $0.003 \mathrm{~m}$. The acrylic sheet is chosen because it is easy to fabricate to the desired shape and for drilling holes to connect the pressure tubes. The base of the building is made of a thick sheet plywood to hold the building model in a fixed position. The actual building dimension for the study is $90 \mathrm{~m}$ and the building are scaled in the ratio 1:300. Pressure measurements are made at three different levels, Level-1 (h/6), Level-2 (h/2), Level$3(4.15 \mathrm{~h} / 5)$, where ' $\mathrm{h}$ ' represents the height of the building model; in total 27 pressure taps are made. Pressure taps are placed at three different heights $50 \mathrm{~mm}(\mathrm{~h} / 6), 150 \mathrm{~mm}(\mathrm{~h} / 2)$ and $250 \mathrm{~mm}(4.15 \mathrm{~h} / 5)$ from the base. On each face of the building model, three pressure taps are made. The building modes are tested for a three-wind incidence direction of about $0^{\circ}, 45^{\circ}$, and $90^{\circ}$ respectively. Figure 3 (a) display the fabricated model of Y-plan shape building, Figure 3 (b) shows the solid work model for Y-plan shape building, Figure 3(c) represents the wind direction for Y-plan shape building. Figures 3 (d) and (e) shows the plan and elevation for $\mathrm{Y}$ shape building with pressure taps location.
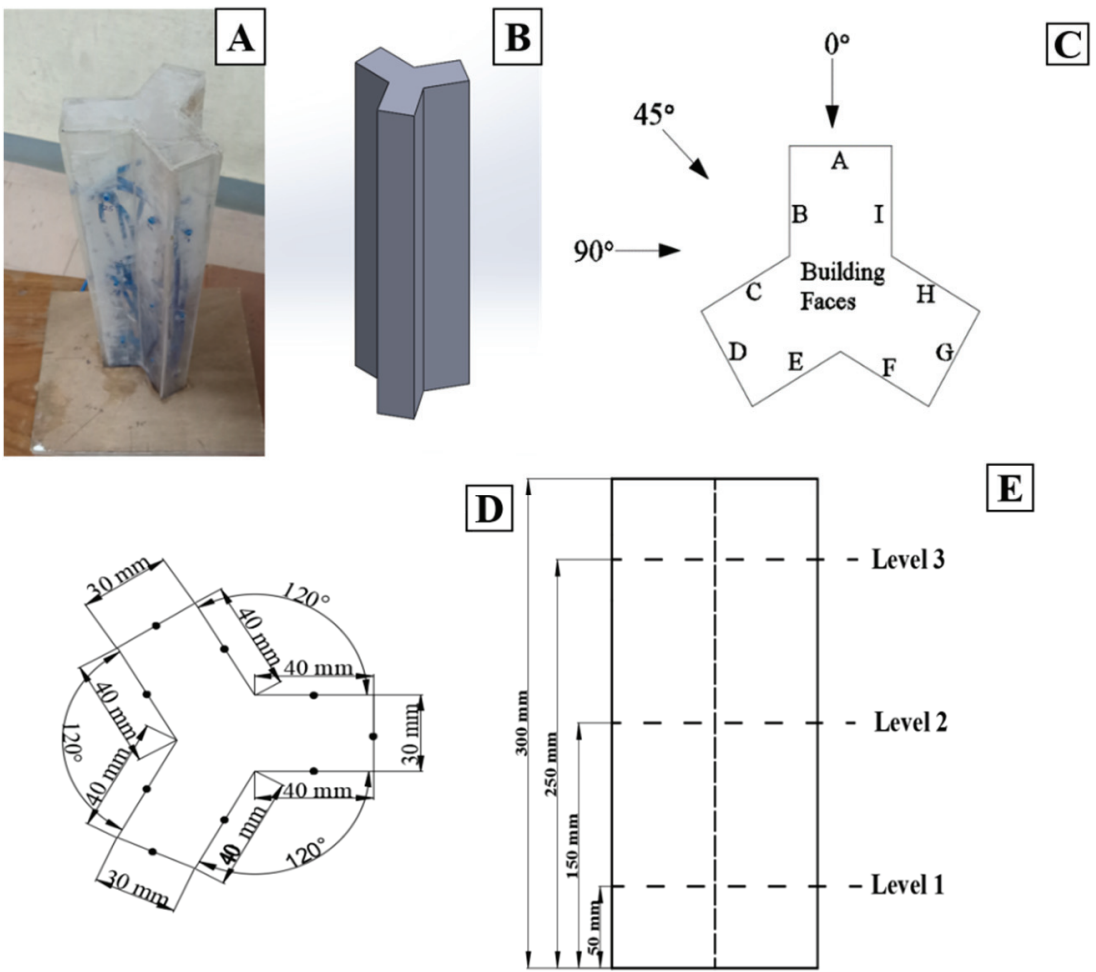

$\mathbf{E}$

Figure 3 - Represents Y-plan shape building (a) Fabricated building model using acrylic sheet (b)Modelling using Solid works (c) Different wind direction angles (d) Plan dimension and location of pressure taps on building model (e) Elevation dimension 


\section{NUMERICAL STUDY}

The numerical study is performed using a turbulence model using realizable $\mathrm{k}-\varepsilon$ available in ANSYS Fluent 19.2 software package. The transport equation involved is momentum $(\mathrm{k})$ and turbulence energy dissipation rate $(\varepsilon)$ are given the equations 1 and 2

$$
\begin{aligned}
& \frac{\partial(\rho \mathrm{k})}{\partial \mathrm{t}}+\frac{\partial}{\partial \mathrm{x}_{\mathrm{j}}}\left(\rho \mathrm{U}_{\mathrm{j}} \mathrm{k}\right)=\frac{\partial}{\partial x_{j}}\left[\left(\mu+\frac{\mu_{t}}{\sigma_{k}}\right) \frac{\partial \varepsilon}{\partial x_{j}}\right]+P_{k}-\rho \varepsilon+P_{k b} \\
& \frac{\partial(\rho \varepsilon)}{\partial t}+\frac{\partial}{\partial x_{j}}\left(\rho U_{j} \varepsilon\right)=\frac{\partial}{\partial x_{j}}\left[\left(\mu+\frac{\mu_{t}}{\sigma_{\varepsilon}}\right) \frac{\partial \varepsilon}{\partial x_{j}}\right]+C_{1} \frac{\varepsilon}{k}\left(P_{k}+C_{3} P_{b}\right)-C_{2} \rho \frac{\varepsilon^{2}}{k}+S_{\varepsilon}
\end{aligned}
$$

Where $\mathrm{P}_{\mathrm{k}}$ is the production due to mean velocity shear, $\mathrm{P}_{\mathrm{b}}$ is the production due to buoyancy, $\mathrm{S}_{\mathrm{k}}$ is a user-defined source. The present study uses a turbulence constants values as stated by the previous authors Jones and Launder [11] and the values are $\sigma_{\mathrm{k}}$ is $1, \sigma_{\varepsilon}$ is $1.3, \mathrm{C}_{1}$ is 1.55 , $\mathrm{C}_{2}$ is $2.0, \mathrm{C}_{\mu}$ is 0.09 respectively. For high Reynolds number, the energy dissipation $\varepsilon$ may be assumed to $\rho k^{1.5} / l$.

$\mu_{t}=\frac{C_{\mu} \rho l k^{2}}{\varepsilon}$

Where, $\mu_{t}$ and $\mathrm{k}$ is nonzero, $\rho$ is the fluid density, $C_{\mu}$ is a constant of value $0.09, l$ is turbulence length scale.

\subsection{Boundary Condition}

The similar boundary condition is adopted for both wind tunnel testing and numerical simulation. The inlet is based on power-law coefficient $(\alpha)$ taken as 0.133

$\frac{U}{U_{0}}=\left(\frac{Z}{z_{0}}\right)^{\alpha}$

Where $\mathrm{U}_{0}$ is the basic wind speed taken as $10 \mathrm{~m} / \mathrm{s}, \mathrm{U}$ is the velocity at a particular height $(\mathrm{Z})$ and $Z_{0}$ is the boundary layer height. Turbulence model realizable $k-\varepsilon$ is used for external flow simulation. The parameters including turbulent kinetic energy $(\mathrm{k})$ and turbulent dissipation rate $(\varepsilon)$ are considered. Turbulent kinetic energy $(\mathrm{k})$ is closely related to turbulent intensity (I) and wind speed (U) [4].

The typical default profile law for setting the Atmospheric Boundary Layer (ABL) may not be suitable for most of the cases. For the present study, ABL is interpreted in the ANSYS Fluent in the form of user-defined coding script as suggested by the authors D.M Hargreaves and N.G Wright [12] for turbulence model k-E. For creating an open terrain profile in CFD, the wall distance $\Delta_{\mathrm{x}}$ should be greater than the roughness height $\left(\Delta_{\mathrm{x}}>\mathrm{K}_{\mathrm{s}}\right)$. The wall function $\mathrm{y}^{+}$is the empirical function, for the current study $\mathrm{y}+$ is 30 , which falls in the log layer and the first cell height distance is $0.002 \mathrm{~m}$. 


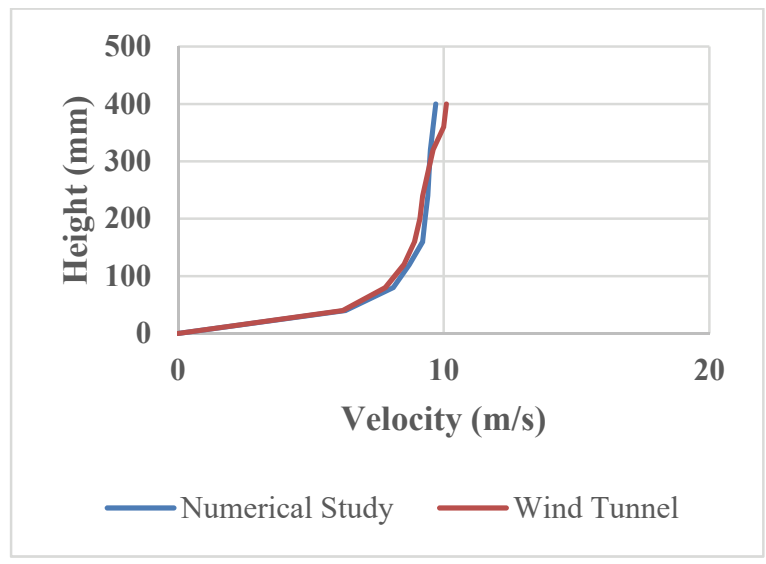

Figure 4 - Velocity profiles

\subsection{Computational Domain Size and Meshing}

The size of the domain is fixed based on the flow simulation. The domain size reference is taken from a recommendation given by Franke et al and Tominaga et al $[13,14]$. The dimension of the domain is $5 \mathrm{H}$ on the upstream side of the building, $15 \mathrm{H}$ in the downstream of the building, and $5 \mathrm{H}$ is considered on the side face of the building, where ' $\mathrm{H}$ ' represents the height of the building inside the computational domain. Figure 5(a) shows the plan view of the computation domain and 5(b) shows the side view of the computation domain. The adopted domain size is very much enough for the generation of a vortex and backflow because of wind. For the present study the inlet boundary condition is $10 \mathrm{~m} / \mathrm{s}$ and is given as per the Equation 4, the outlet boundary condition is $\frac{\partial}{\partial x}(u, v, w, k, \varepsilon)=0$, No-slip is considered on the floor of the computational domain ensuring that no velocity had occurred between the wall and the moving fluids, $\mathrm{u}=\mathrm{v}=\mathrm{w}=0$ and the free slip is considered in the top and sidewall of the computational domain $\frac{\partial}{\partial x}(u, v, w, k, \varepsilon)=0$.

Finite element tetrahedral mesh element is used throughout the domain. Grid quality and quantity determine computation time and cost. Mesh in the building is made to be fine when compared to the computational domain [19]. Grid independency test is performed namely coarse grid, basic grid and fine grid and the results are displayed in table 1. Figure 6(a) shows the grid generation over the entire domain, Figure 6(b) shows the grid generation closer to Y-plan shape building.

Table 1 - Grid sensitivity study and grid size

\begin{tabular}{cccc}
\hline Name & $\boldsymbol{\Delta}_{\mathbf{x}}(\mathbf{m})$ & No of Node & No. of Elements \\
\hline Course grid & 0.0025 & 530314 & 2832920 \\
\hline Basic & 0.0020 & 736719 & 3392253 \\
\hline Fine & 0.0020 & 2509599 & 8067948 \\
\hline
\end{tabular}




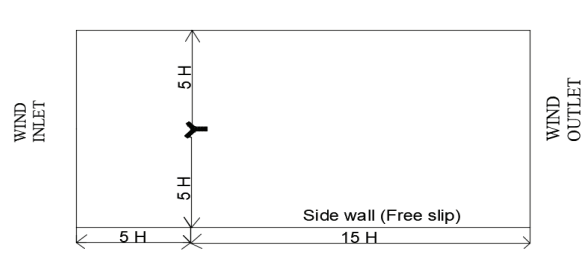

(a)

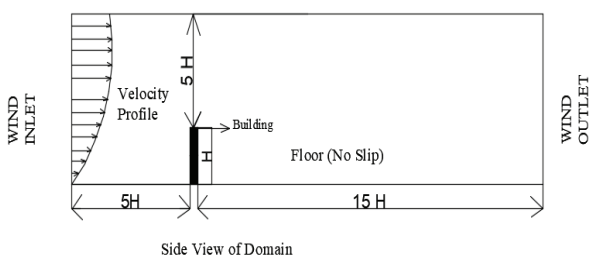

(b)

Figure 5 - Computational domain size (a) Plan view of Computational domain (b) Size view of the Computational domain

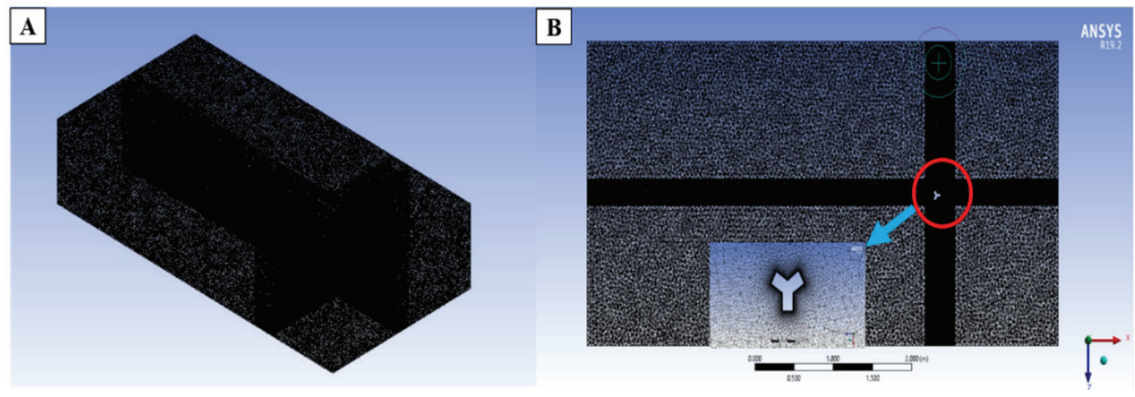

Figure 6 - Grid generation (a) Overall grid distribution over the entire domain (b) Grid generation closer to Y-plan shape building surface.

\subsection{Solver Settings}

The numerical simulation is performed using ANSYS Fluent 19.2 commercial software package. The simulation is solved using steady-state, 3-D Reynolds Averaged Navier-Stokes Equation (RANS) equation is incorporated in ANSYS Fluent software. Since the flow over a building model is an incompressible flow, the Mach number is less than three $(\mathrm{M}<3)$. Pressure based velocity coupling solver is used and turbulence model reliable k- $\varepsilon$ is used for the present study. Many previous studies prove that reliable turbulence model $\mathrm{k}-\varepsilon$ is good to capture the flow involving rotations, flow separation and recirculation. The Semi-Implicit Method for Pressure Linked Equations (SIMPLE) algorithm is used for coupling pressure and velocity. Second-order discretization schemes are used for solving the governing equation involving convection and viscous terms. The simulation is performed using Intel $9^{\text {th }}$ Generation Core i5, running at $1.9 \mathrm{GHz}$ with $8 \mathrm{G}$.B internal memory. The iterations were performed when the convergence of the variable momentums in $\mathrm{X}, \mathrm{Y}$ and $\mathrm{Z}$ direction, continuity, $\mathrm{k}$ and $\varepsilon$ are archived when the residual reaches a value of $1 \times 10^{-4}$. 


\section{RESULTS AND DISCUSSIONS}

\subsection{Pressure Distribution around the Buildings}

Knowledge of external pressure distribution is very much important to evaluate the wind loads on various structural components. Pressure distribution around the building at various faces is investigated for the wind angles $0^{\circ}, 45^{\circ}$ and $90^{\circ}$ respectively. The wind flow pattern depends on ground roughness, velocity profiles, computational domain, grid spacing, etc. Previous researchers conducted [4] a numerical simulation and investigated the pressure distribution around rectangular buildings with varying dimensions and validation is done with the CAARC building model to check the accuracy of CFD results. Validation of CFD results with the experimental studies is very much important for all computational studies [24]. Validation gives us a high degree of accuracy to represent all real-world problems. The investigation of CFD results in this paper is compared with the experimental wind pressure values and are checked for its accuracy. The mean pressure coefficient $\left(\mathrm{C}_{\mathrm{p}}\right)$ is a nondimensional parameter and calculated using equation 5 .

$\mathrm{C}_{\mathrm{p}, \text { mean }}=\frac{p-p_{0}}{\frac{1}{2} \rho U_{H}^{2}}$

Where $\mathrm{p}$ is the pressure value from the point needed, $\mathrm{p}_{0}$ is the pressure at reference height, $\rho$ is the density of air of value $1.225 \mathrm{~kg} / \mathrm{m}^{3}, U_{H}^{2}$ is the mean wind velocity.

\subsection{Blockage Correction}

Blockage correction is introduced by Maskell in the year 1958 [15], to reduce the overestimated flow obtained from wind tunnel. Since the blockage ratio is more than $5 \%$ for the present study, the necessary blockage corrections are made using the equation 6 .

$\mathrm{C}_{\mathrm{p}, \text { Corrected }}=\frac{C_{p, m}}{n}+\frac{(n-1)}{n}$

Where $\mathrm{n}$ is the blockage correction factor. Table 3 shows the blockage correction for $\mathrm{C}$ plan shape building for wind angles $0^{\circ}, 45^{\circ}$ and $90^{\circ}$ respectively.

Table 2 - Blockage correction (n) for C-plan shape building with different wind angles

\begin{tabular}{ccc}
\hline $\begin{array}{c}\text { Wind } \\
\text { angles }\end{array}$ & $\begin{array}{c}\text { Blockage } \\
\text { value (\%) }\end{array}$ & $\begin{array}{l}\text { Blockage } \\
\text { correction (n) }\end{array}$ \\
\hline $0^{\circ}$ & 11.383 & 1.0638 \\
\hline $45^{\circ}$ & 10.925 & 1.5925 \\
\hline $90^{\circ}$ & 10.067 & 1.5067 \\
\hline
\end{tabular}




\subsection{Pressure Distribution on Building Faces}

For the design of tall building one of the most important parameters to be considered in wind load is the pressure coefficient $\left(C_{p}\right)$ [17]. Usually, windward faces of the building experience positive $C_{p}$ and leeward and side faces experience negative $C_{p}$. The mean $C_{p}$ on various faces of the Y-plan shape building model is investigated using wind tunnel and CFD. Figure 7 shows the comparison of mean $C_{p}$ for the wind angles $0^{\circ}, 45^{\circ}$ and $90^{\circ}$ obtained from wind tunnel testing. Figure 8 shows the comparison of mean $C_{p}$ for the wind angles $0^{\circ}, 45^{\circ}$ and $90^{\circ}$ obtained using realizable $\mathrm{k}-\varepsilon$ turbulence model using CFD.

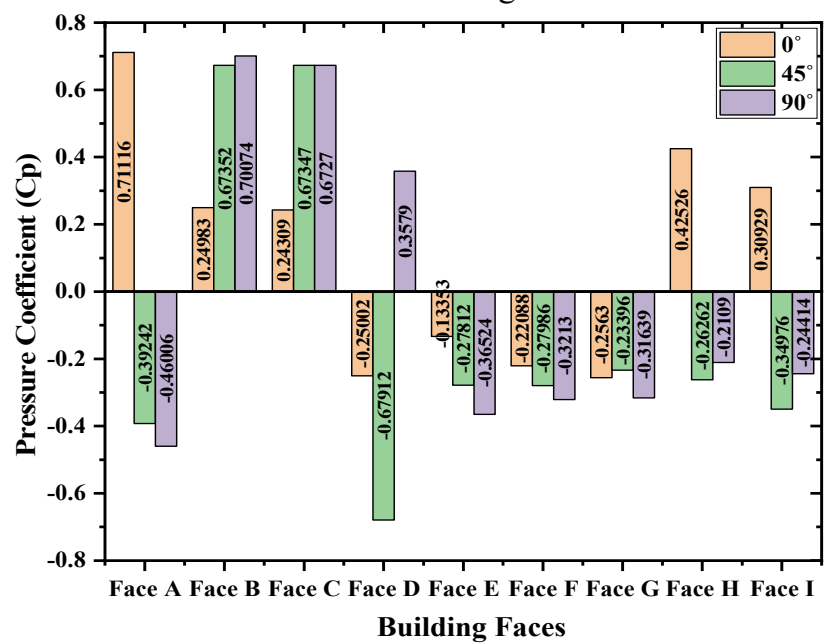

Figure 7 - Comparison of face pressure coefficient for different angles $0^{\circ}, 45^{\circ}$ and $90^{\circ}$ from Wind tunnel testing

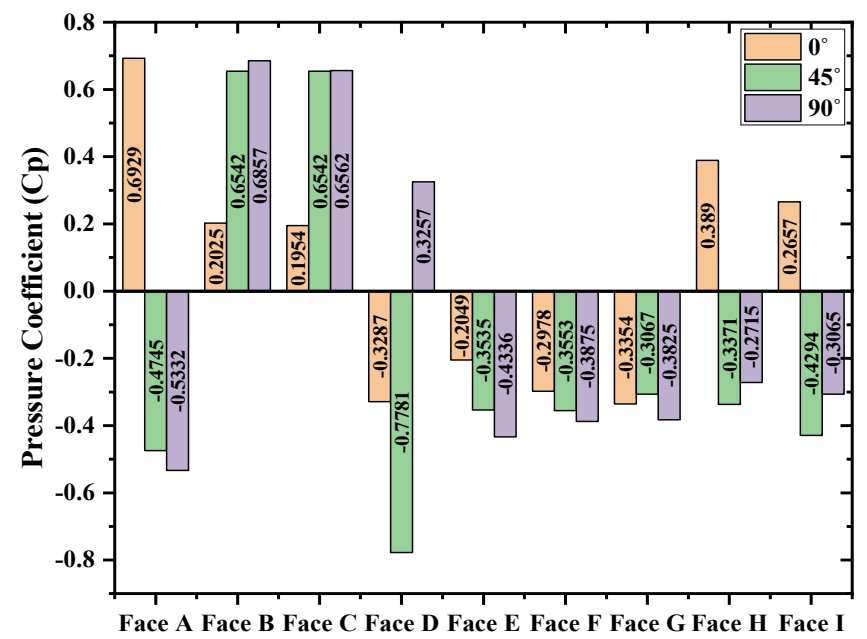

Building Faces

Figure 8 - Comparison of face pressure coefficient for different angles $0^{\circ}, 45^{\circ}$ and $90^{\circ}$ from CFD results 


\subsection{Angle of Incidence - $0^{\circ}$}

For $0^{\circ}$ Angle of Incidence (AoI), building faces A, B, C, H, and I experience positive pressure coefficient $\left(\mathrm{C}_{\mathrm{p}}\right)$, whereas faces $\mathrm{D}, \mathrm{E}, \mathrm{F}$, and $\mathrm{G}$ experience a negative pressure coefficient $\left(\mathrm{C}_{\mathrm{p}}\right)$. It is noticeable that high positive $C_{p}$ is observed in the face A of about 0.6929 in CFD and 0.7116 from the wind tunnel test. On the other hand, very low negative pressure coefficient $\left(\mathrm{C}_{\mathrm{p}}\right)$ is observed in face $\mathrm{D}$ of about -0.3287 in CFD and -0.2500 in wind tunnel test. Table 3 shows the comparison of mean $\mathrm{C}_{\mathrm{p}}$ with turbulence model realizable $\mathrm{k}-\varepsilon$ in $\mathrm{CFD}$ and wind tunnel test for $0^{\circ}$ wind angle.

The pressure coefficient contour for the building faces A, B, C, D, E, F, G, H, and I for $0^{\circ}$ wind angle are displayed in figure 9 . The pressure contour on different faces provides very useful information regarding the distribution of the pressure on the various heights of the building. Most of the present Wind Engineering Code (WEC) provides a single mean $\mathrm{C}_{\mathrm{p}}$ for the entire face of a regular plan geometry; but in the actual condition the value of $\mathrm{C}_{\mathrm{p}}$ varies along with the height of the building. Further positive $C_{p}$ decreases along the edges due to dispersion of flow in the windward face and negative $C_{p}$ increases along the edge as noticed by the author [18] K. Suresh Kumar. For the present study in the distribution of the pressure on each face of the building as representing in figure 9 , face $A$ experiences high positive $C_{p}$ and the pressure decreases along the top and side edges in face A of the building due to the windward direction. However, for the faces D, E, F, G undergoes negative $\mathrm{C}_{\mathrm{p}}$ because of leeward direction and the negative $\mathrm{C}_{\mathrm{p}}$ increases along the edges for the leeward building faces due to convergence of flow from the top. Figure 10 shows the $C_{p}$ that is measured around the perimeter of the building with different heights $h / 6, h / 2,4.15 \mathrm{~h} / 5$ for $0^{\circ}$ wind angle. The $\mathrm{C}_{\mathrm{p}}$ on windward sides experience equal $C_{p}$ on all the three height $(h / 6, h / 2,4.15 \mathrm{~h} / 5)$ along the perimeter from 0 to $15 \mathrm{~m}$, whereas the pressure in the leeward sides experience a high negative $C_{p}$ at the height of $4.15 \mathrm{~h} / 5$. This proves that the negative pressure is high in the leeward face top of the building.

Table 3 - Comparison of mean pressure coefficient on different faces for $0^{\circ}$ wind angle

\begin{tabular}{|c|c|c|c|}
\hline \multirow[t]{2}{*}{ Location } & \multicolumn{2}{|c|}{ Mean $C_{p}$} & \multirow[t]{2}{*}{ Remarks } \\
\hline & $\mathbf{k}-\varepsilon$ & Wind tunnel & \\
\hline Face A & 0.6929 & 0.7111 & \multirow{9}{*}{$\begin{array}{l}\text { All results } \\
\text { are within } \\
\text { the } \\
\text { acceptable } \\
\text { limits }\end{array}$} \\
\hline Face B & 0.2025 & 0.2498 & \\
\hline Face C & 0.1954 & 0.2500 & \\
\hline Face D & -0.3287 & -0.2500 & \\
\hline Face E & -0.2049 & 0.2500 & \\
\hline Face F & -0.2978 & 0.1335 & \\
\hline Face $\mathrm{G}$ & -0.3354 & -0.2208 & \\
\hline Face H & 0.3890 & 0.4252 & \\
\hline Face I & 0.2657 & 0.3092 & \\
\hline
\end{tabular}



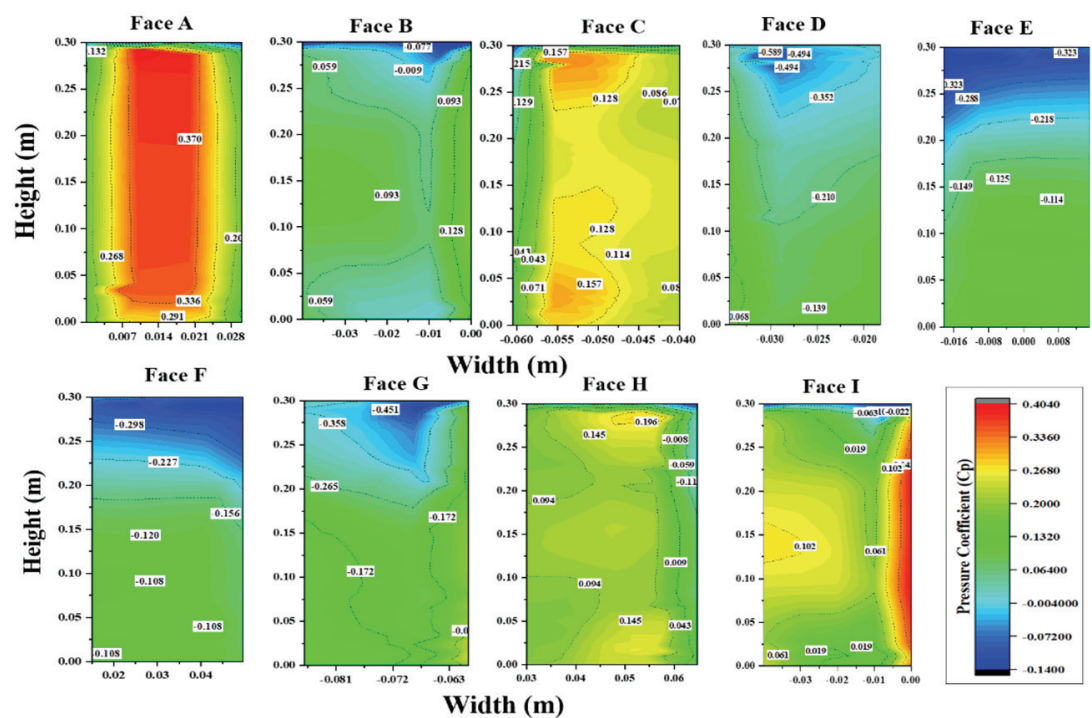

Figure 9 - Represents the pressure coefficient $\left(C_{p}\right)$ contour on various faces for $0^{\circ}$ wind angle

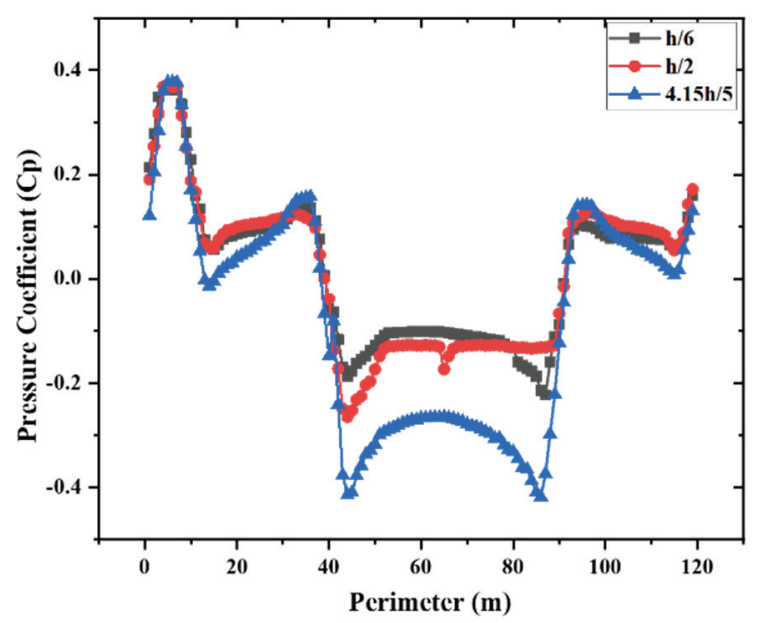

Figure 10 - Pressure coefficient $\left(C_{p}\right)$ along the perimeter of $Y$-plan shape building for $0^{\circ}$ wind angle

\subsection{Angle of Incidence $-45^{\circ}$}

For $45^{\circ}$ AoI building faces $\mathrm{B}$ and $\mathrm{C}$ experience positive coefficient $\left(\mathrm{C}_{\mathrm{p}}\right)$, whereas faces $\mathrm{A}, \mathrm{D}$, $\mathrm{E}, \mathrm{F}, \mathrm{G}, \mathrm{H}$, and I experience negative pressure coefficient $\left(\mathrm{C}_{\mathrm{p}}\right)$. Obviously, high positive pressure coefficient $\left(\mathrm{C}_{\mathrm{p}}\right)$ is experienced in windward faces of the building $\mathrm{B}$ and $\mathrm{C}$ of about 0.6542 from $\mathrm{CFD}$ and 0.6735 from the wind tunnel. Further, very low negative pressure 
coefficient $(\mathrm{Cp})$ is experienced in the face $\mathrm{G}$ of about -0.3067 from CFD and -0.2339 from the wind tunnel testing. Table 4 shows the comparison of surface pressure coefficient with CFD and wind Tunnel testing for $45^{\circ}$ wind angle.

Table 4 - Comparison of mean surface pressure coefficient on different faces for $45^{\circ}$ wind angle

\begin{tabular}{|c|c|c|c|}
\hline \multirow[t]{2}{*}{ Location } & \multicolumn{2}{|c|}{ Mean $C_{p}$} & \multirow[t]{2}{*}{ Remarks } \\
\hline & $\mathbf{k}-\varepsilon$ & Wind tunnel & \\
\hline Face A & -0.4745 & -0.3924 & \multirow{9}{*}{$\begin{array}{l}\text { All results are } \\
\text { within the } \\
\text { acceptable } \\
\text { limits }\end{array}$} \\
\hline Face B & 0.6542 & 0.6735 & \\
\hline Face C & 0.6542 & 0.6732 & \\
\hline Face D & -0.7781 & -0.6791 & \\
\hline Face E & -0.3535 & -0.2781 & \\
\hline Face $\mathrm{F}$ & -0.3553 & -0.2798 & \\
\hline Face $\mathrm{G}$ & -0.3067 & -0.2339 & \\
\hline Face $\mathrm{H}$ & -0.3371 & -0.2626 & \\
\hline Face I & -0.4294 & -0.3497 & \\
\hline
\end{tabular}
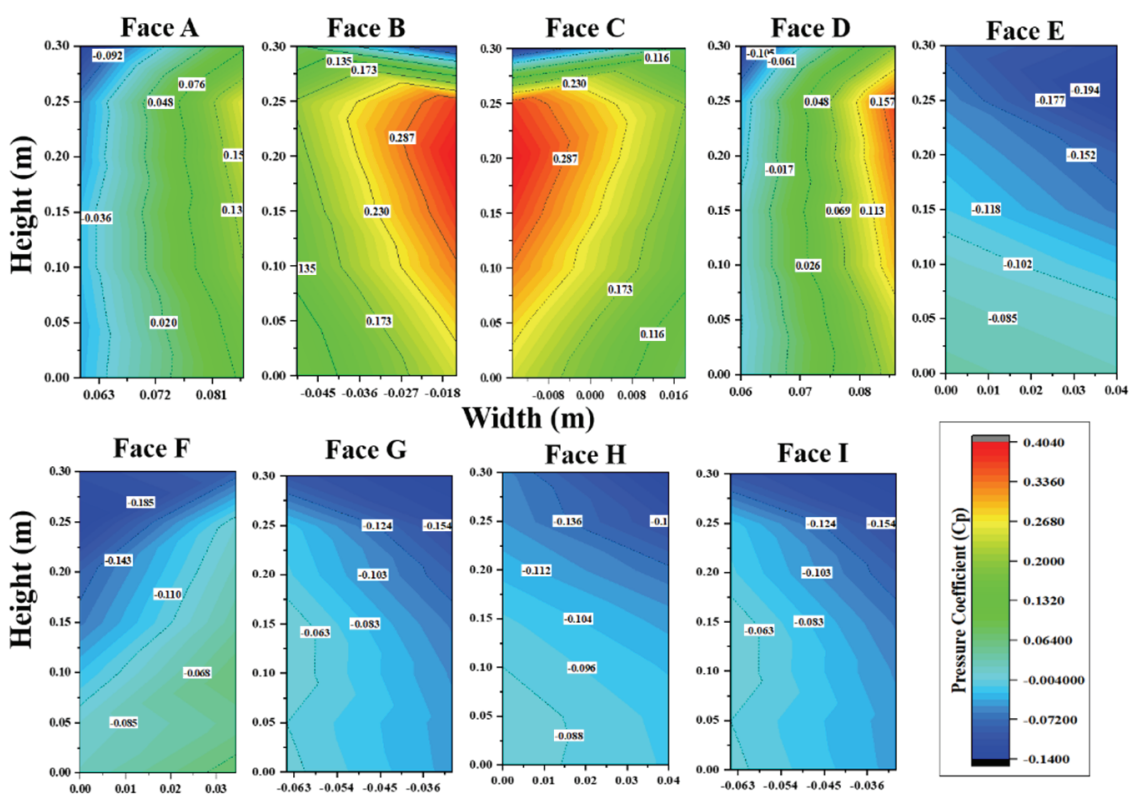

Width (m)
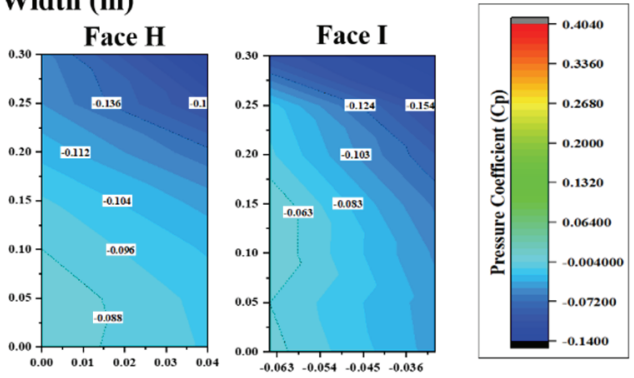

Width (m)

Figure 11 - Represents the pressure coefficient $\left(C_{p}\right)$ contour on various faces for $45^{\circ}$ wind angle 
Figure 11 shows the wind pressure distribution on Y-plan shaped building for $45^{\circ}$ wind angle. High positive pressure contour is observed in the faces $B$ and $C$, further the pressure contour decreases along the side faces of the building as represented in figure 11. Due to symmetrical flow of wind, faces $\mathrm{B}$ and $\mathrm{C}$ experiences similar mirror contour pressure, as shown in the figure 11 . Whereas, $90 \%$ similar contour pressure is observed in the leeward faces $\mathrm{E}, \mathrm{F}, \mathrm{G}$, $\mathrm{H}$, and I of the building. High positive pressure decreases along the top edges of the building faces $\mathrm{B}$ and $\mathrm{C}$, because of the dispersion of the flow along the top edges of the building.

The pressure measurement is measured along the perimeter of the building at different heights $\mathrm{h} / 6, \mathrm{~h} / 2,4.15 \mathrm{~h} / 5$ for $45^{\circ}$ wind angle. Figure 12 indicates the pressure coefficient $\left(\mathrm{C}_{\mathrm{p}}\right)$ along the perimeter of the building at three different heights. Minor variation in pressure coefficient $\left(\mathrm{C}_{\mathrm{p}}\right)$ is observed in the positive faces at different levels. Similar negative pressure is observed in the leeward face for the heights $\mathrm{h} / 6, \mathrm{~h} / 2$ and further major deviation in pressure coefficient $\left(\mathrm{C}_{\mathrm{p}}\right)$ has occurred at bottom level $4.15 \mathrm{~h} / 5$.

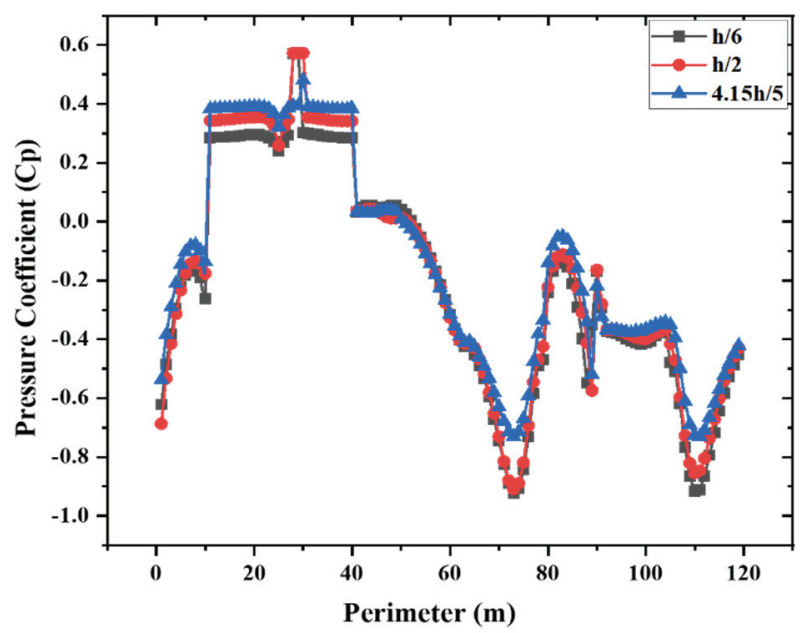

Figure 12 - Pressure coefficient $\left(C_{p}\right)$ along the perimeter of $Y$-plan shape building for $45^{\circ}$ wind angle

\subsection{Angle of Incidence - $90^{\circ}$}

For $90^{\circ}$ AoI, building faces $\mathrm{B}, \mathrm{C}$, and $\mathrm{D}$ experience positive pressure coefficient $\left(\mathrm{C}_{\mathrm{p}}\right)$; whereas the faces $A, E, F, G, H$, and I experience negative pressure coefficient $\left(\mathrm{C}_{\mathrm{p}}\right)$. High positive pressure coefficient $\left(\mathrm{C}_{\mathrm{p}}\right)$ is observed in the face $\mathrm{B}$ of about 0.6857 from CFD and 0.7007 from wind tunnel testing and furthermore, very low negative pressure coefficient $\left(\mathrm{C}_{\mathrm{p}}\right)$ is observed in the face $\mathrm{A}$ of about -0.5484 . Table 5 shows the comparison of the mean pressure coefficient for the $90^{\circ}$ wind angle.

Figure 13 shows the wind pressure distribution contour on Y-plan shape building for $90^{\circ}$ wind angle. As expected for all the wind angles, the middle position of the windward faces experience high positive wind pressure distributions along the perimeter of the buildings. The windward faces $B, C$ and $D$ experience positive pressure coefficient $\left(C_{p}\right)$, whereas in the faces 
$\mathrm{B}$ the pressure gets reduces at the top faces due to the dispersion of flow at the top and for the faces $\mathrm{C}$ and $\mathrm{D}$, the pressure reduces along the sides and the top faces of the building model. Moreover, $80 \%$ similar contour pressure distribution is observed in the leeward face the building A, G and $\mathrm{H} ; 90 \%$ of the similar pressure is observed in the faces $\mathrm{E}$ and I. Negative pressure coefficient $\left(\mathrm{C}_{\mathrm{p}}\right)$ increase along with the top corners of the building due to the convergence of the flow.

Table 5 - Comparison of mean surface pressure coefficient on different faces for $90^{\circ}$ wind angle

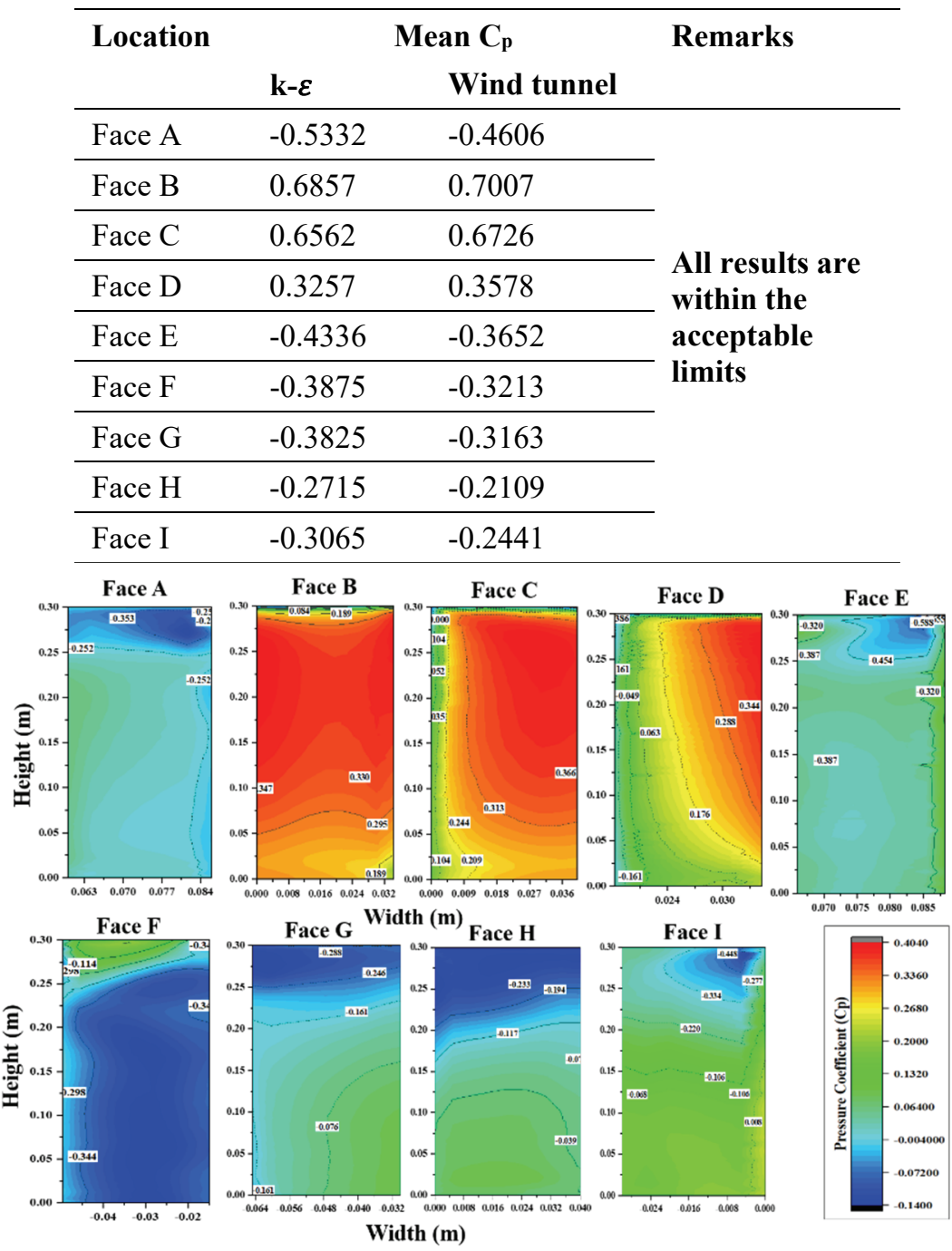

Figure 13 - Represents the pressure coefficient $\left(C_{p}\right)$ contour on various faces for $90^{\circ}$ wind angle 
Figure 14 shows the pressure measurement along the perimeter of the building at three different levels $\mathrm{h} / 6, \mathrm{~h} / 2,4.15 \mathrm{~h} / 5$. Similar pressure coefficient $\left(\mathrm{C}_{\mathrm{p}}\right)$ is observed in the windward faces for the levels of height $h / 6$ and $h / 2$, whereas a mild deviation is observed leeward faces for the levels $\mathrm{h} / 6$ and $\mathrm{h} / 2$ respectively. On the contrary, for the top height $4.15 \mathrm{~h} / 5$ experiences a huge negative pressure coefficient $\left(\mathrm{C}_{\mathrm{p}}\right)$ for the faces $\mathrm{G}$ and $\mathrm{H}$.

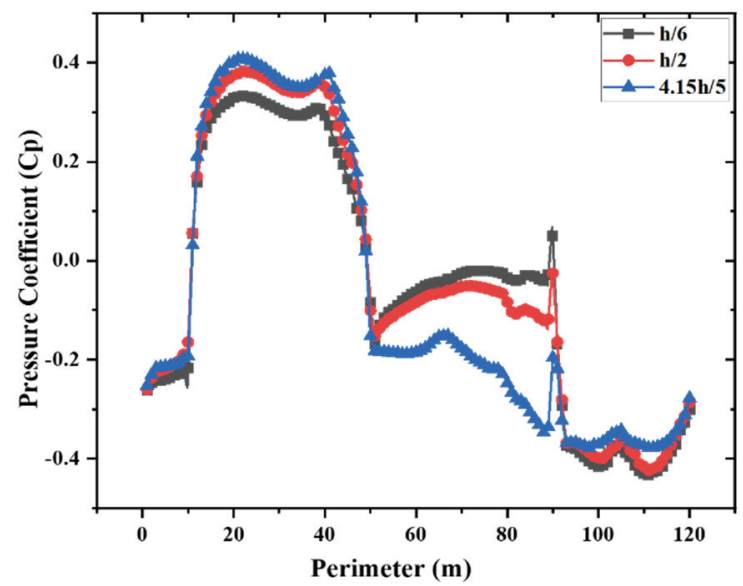

Figure 14 - Pressure coefficient $\left(C_{p}\right)$ along the perimeter of Y-plan shape building for $90^{\circ}$ wind angle

\subsection{Error Analysis}

Error analysis is performed using Coefficient of determination $\mathrm{R}^{2}$, Mean percentage Error (ME), Root Mean Square Error (RMSE) and Mean Absolute Percentage Error (MAPE). Table 6 shows the error analysis for $\mathrm{R}^{2}, \mathrm{ME}, \mathrm{RMSE}$ and MAPE for all the predicted $\mathrm{C}_{\mathrm{p}}$. The value of $\mathrm{R}^{2}$, ME, RMSE and MAPE is calculated using the equation 7, 8, 9 and 10 respectively.

Coefficient of determination $R^{2}=\frac{\sum(\hat{y}-\bar{y})^{2}}{\sum\left(y_{i}-\overline{y_{i}}\right)^{2}}$

$\hat{y}=$ CFD value (actual), $\bar{y}=$ Average of observed value, $y_{i}=$ Wind Tunnel reading (observed Exp), $\overline{y_{i}}=$ Average of all reading.

Mean absolute error is calculated (MAE) from $=\frac{1}{n} \sum_{i=1}^{n}\left(x_{i}-x\right)$

where, $x_{i}=$ Exp Value, $\mathrm{x}=\mathrm{CFD}$ value

Root mean square error $(\mathrm{RMSE})=\sum_{i=1}^{N}\left[\frac{\left(Z_{f i}-Z_{0 i}\right)^{2}}{N}\right]^{1 / 2}$

Where, $Z_{f i}=C F D$ value and $Z_{0 i}=$ Exp value and Mean absolute percentage error is

calculated (MAPE) from $=\frac{1}{n} \sum_{i=1}^{n} \frac{\mid(\text { Actual-Forecost }) \mid}{\text { Actual }} X 100$ 
Previous researcher [27] have carried out error analysis by comparing a wind tunnel and CFD results for the building of C-plan shape building and rectangular building with an opening. Table 6 displays the error analysis for the present study using $\mathrm{R}^{2}, \mathrm{ME}$, RMSE and MAPE. From the results the calculated value of $\mathrm{R}^{2}$ is 0.9 , which shows a very good curve fitting and for RMSE $>0.5$ is a good result and other data MAE and MAPE are also within the permissible error limits for all the building faces.

Table 6 - Error analysis of predicted $C_{p}$ for the model

\begin{tabular}{ccccc}
\hline $\begin{array}{c}\text { Building } \\
\text { Faces }\end{array}$ & $\mathbf{R}^{\mathbf{2}}$ & MAE & RMSE & MAPE \\
\hline A & 0.9 & 0.0284 & 0.0306 & 2.7513 \\
\hline B & 0.9 & 0.0175 & 0.0194 & 3.3782 \\
\hline C & 0.9 & 0.0256 & 0.0283 & 8.6880 \\
\hline D & 0.9 & 0.0201 & 0.0221 & 1.7195 \\
\hline E & 0.9 & 0.0487 & 0.0509 & 17.8990 \\
\hline F & 0.9 & 0.0321 & 0.0342 & 8.9875 \\
\hline G & 0.9 & 0.0374 & 0.0401 & 11.0106 \\
\hline
\end{tabular}

\subsection{Wake Regions}

Wake regions are created in the downstream of the building because of the low wind velocity and turbulence. Usually for a bluff body such as buildings, the region of wake formation is large and smaller wake are found in streamline bodies. For Y plan shape building, broad wakes are observed in the leeward face of the building for the wind angles $0^{\circ}, 45^{\circ}$ and $90^{\circ}$. The size of the wake depends on the shape of the body and type of turbulence flow. Figures $15(\mathrm{a}),(\mathrm{b})$ and (c) display the wake formation for the wind angles $0^{\circ}, 45^{\circ}$ and $90^{\circ}$.

\subsection{Numerically Predicted Wind Flow}

In figures 16(a), (b) and (C) presents the numerically predicted velocity flow patterns for the wind angles $0^{\circ}, 45^{\circ}$ and $90^{\circ}$. Prior researcher Rajasekarababu et al and Prasenjit Sanyal et al $[16,25]$ observed the flow pattern for setback buildings for wind angles $0^{\circ}$ and $90^{\circ}$ respectively. For all the wind directions the wind passes sharply from the inlet and strikes the building. In addition, the flow separation occurs at the corners which leads to the formation of negative pressures. In the figures 16 (a to c) the numbering are made from 1 to 9 in order to study physics of the flow pattern behind Y-plan shape tall building, number 1 in the figures 16 (a), (b) and (c) indicate the separation point where the flow gets separated, Number 2 indicates the shear layer, Number 3 indicates the recirculation regions, Number 4 indicates flow above the building, Number 5 indicates oncoming flow, Number 6 indicates stagnation flow, Number 7 indicates corner streamlines, Number 8 indicates Recirculation cavity due to suction, Number 9 indicates the expansion of wake regions. When the wind flow hits the building surface the flow gets separated and results in the formation of the vortex on the downstream of the bluff bodies such as a building. 


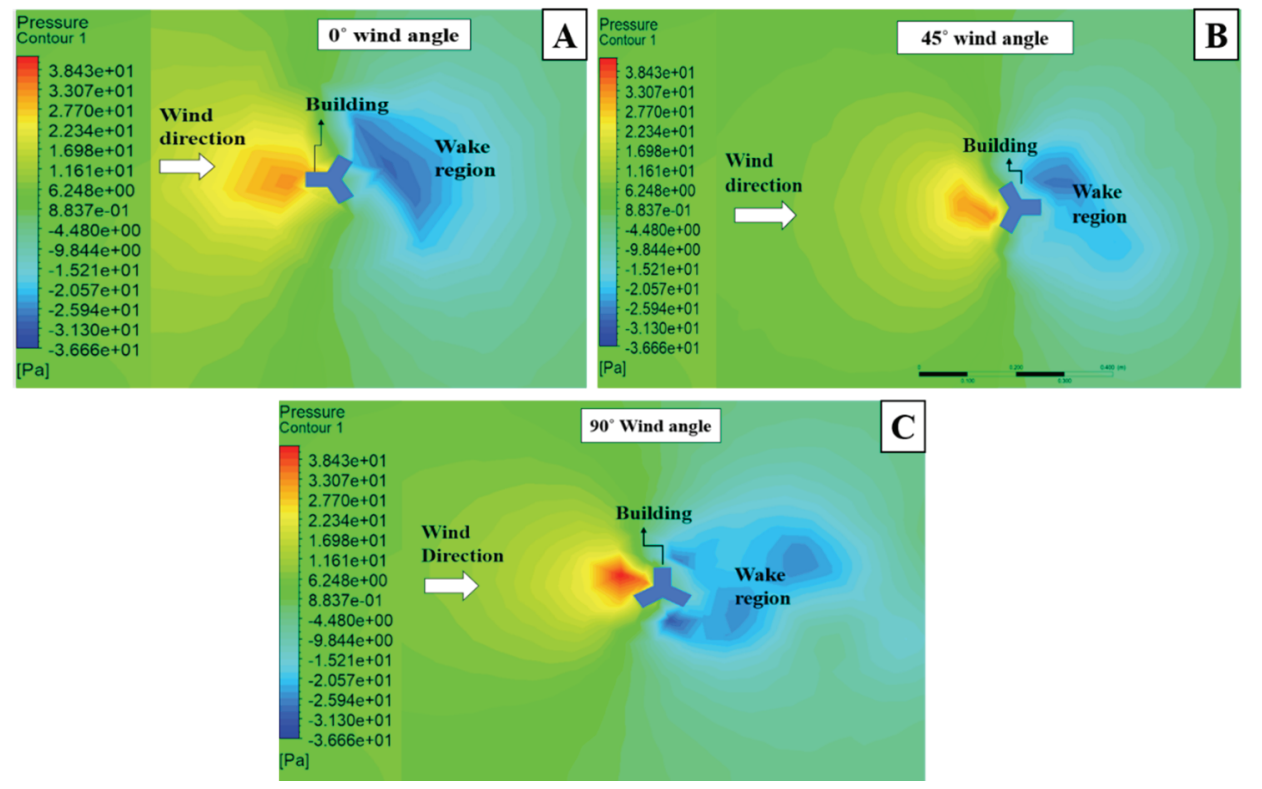

Figure 15 - Identification of wake regions (a) $0^{\circ}$ wind angle (b) $45^{\circ}$ wind angle (c) $90^{\circ}$ wind angle
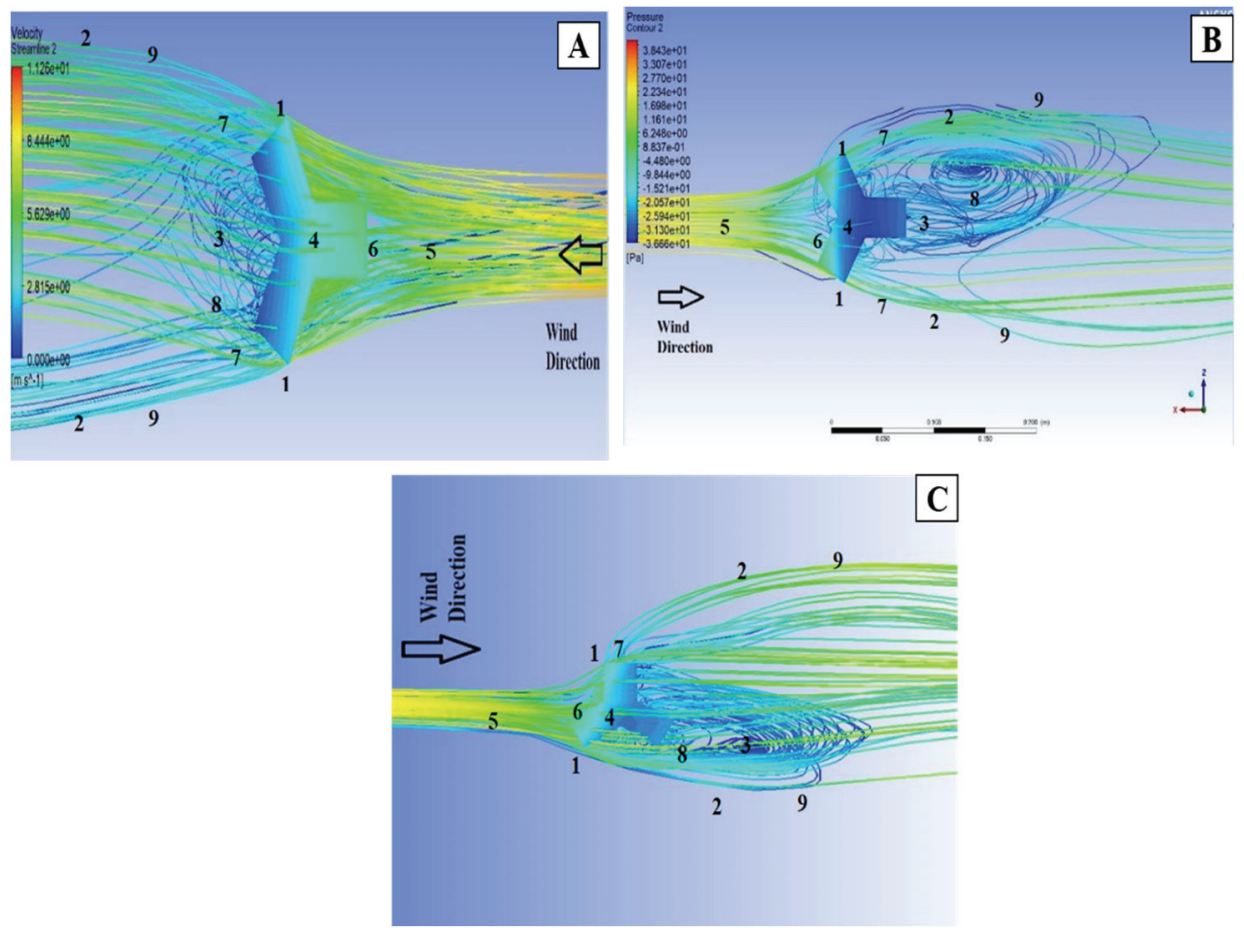

Figure 16 - Wind Flow pattern (a) $0^{\circ}$ wind angle (b) $45^{\circ}$ wind angle (c) $90^{\circ}$ wind angle 


\subsection{Drag and lift coefficient}

Cantilever structures such as buildings presented above the earth are subject to along wind, crosswind and torsional moment. Drag forces are caused due to along-wind force (i.e forces parallel to the body), lift forces are generated due to crosswind force (i.e perpendicular to along wind direction) and torsional moments are due to twisting of buildings [20]. The aerodynamic coefficients for buildings are found by using the following formula.

$$
\begin{aligned}
& C_{\text {D mean }}=\frac{F_{D}}{\frac{1}{2} \rho V_{H}^{2} A} \\
& \mathrm{C}_{\mathrm{L} \text { mean }}=\frac{F_{L}}{\frac{1}{2} \rho V_{H}^{2} A}
\end{aligned}
$$

$\mathrm{C}_{\mathrm{D} \text { mean }}$ and $\mathrm{C}_{\mathrm{L} \text { mean }}$ are the drag and lift coefficient respectively. $\mathrm{F}_{\mathrm{D}}$ represents the drag force, $\mathrm{F}_{\mathrm{L}}$ represents lift force, $\rho$ represents the density of air, $\mathrm{V}$ represents a velocity of wind, A represents projected area.

The discussion about the drag and lift coefficient for the Y-plan shape building model for the particular wind velocity $10 \mathrm{~m} / \mathrm{s}$ is made. The drag coefficient $\left(\mathrm{C}_{\mathrm{D}}\right)$ for $0^{\circ}$ wind angle is 1.066 and the lift coefficient $\left(\mathrm{C}_{\mathrm{L}}\right)$ is 1.224 . With regard to $45^{\circ}$ wind angle, drag coefficient $\left(\mathrm{C}_{\mathrm{D}}\right)$ is 1.656 and lift coefficient $\left(\mathrm{C}_{\mathrm{L}}\right)$ is 1.662 . Further with respect to $90^{\circ}$ wind angle, drag coefficient $\left(\mathrm{C}_{\mathrm{D}}\right)$ is 1.648 and lift coefficient $\left(\mathrm{C}_{\mathrm{L}}\right)$ is 1.458 . Maximum drag is found at $45^{\circ}$ wind angle because it has less projected area when compared with all the other wind angles, followed by a $90^{\circ}$ wind angle and $0^{\circ}$ wind angle. The results of the drag force indicate that the drag force depends on the frontal area of the building i.e. façade or elevation. In order to reduce the drag force on buildings, modifications have to be done in elevations, building façade design. Many previous researchers [21,22 and 23] have worked on building modification in order to reduce the drag and lift coefficient on the buildings. Figure 17 shows the drag and lift coefficient for Y-plan shape building with wind angles $0^{\circ}, 45^{\circ}$ and $90^{\circ}$.

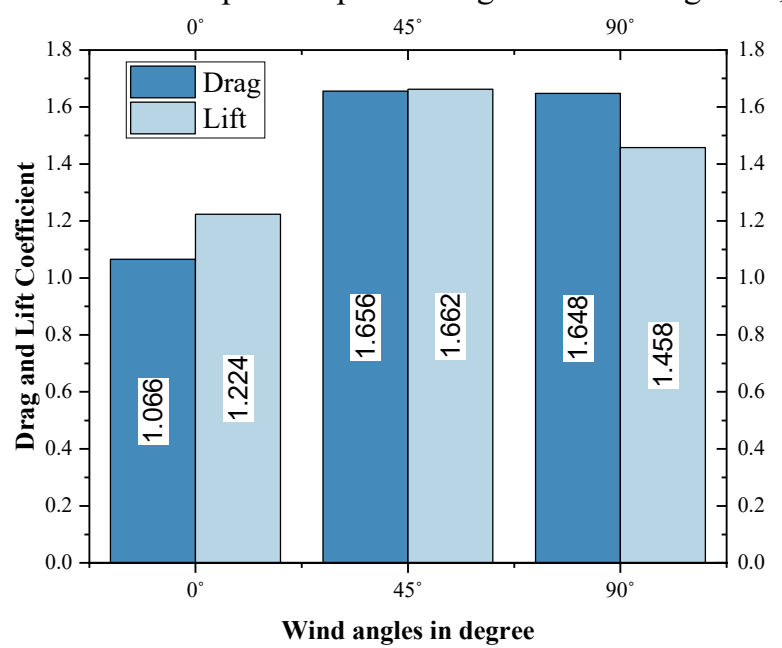

Figure 17 - shows the drag and lift coefficient for Y-plan shape buildings with wind angles $0^{\circ}, 45^{\circ}$ and $90^{\circ}$ 


\section{CONCLUSIONS}

Systematic wind pressure measurements are conducted to investigate the effect of wind flow around the Y-plan shape tall buildings. From the analysis of CFD and wind tunnel testing, it is possible to have an evident result in pressure distributions on various faces of the building at different wind angles. From the above study, the following conclusions are drawn.

- From the results of wind tunnel and CFD it is evident that high positive pressure coefficient $\left(\mathrm{C}_{\mathrm{p}}\right)$ is observed in face $\mathrm{A}$, at $0^{\circ}$ wind angle followed by faces $\mathrm{B}$ and $\mathrm{C}$ for $45^{\circ}$ wind angle and further succeeded by the face $\mathrm{B}$ for $90^{\circ}$ wind angle. Besides high negative pressure coefficient $\left(C_{p}\right)$ is observed in face $G$ for $0^{\circ}$ wind angle, followed by face $\mathrm{D}$ for $45^{\circ}$ wind angle and further succeeded by face $\mathrm{A}$ for $90^{\circ}$ wind angle.

- With regard to the pressure measurement along the perimeter of the building, a mild variation in the pressure at the top height $4.15 \mathrm{~h} / 5$ is observed. For windward face the pressure reduces in the top height and in the leeward face the pressure increases. Whereas in the pressure distribution in the middle and lower height only a mild differences in pressure fluctuation occurs.

- With the support of turbulence model, realizable k- $\varepsilon$ is very much useful for finding the external flow behaviour around the building such as stagnation flow, recirculation cavity, corner streamlines, etc. as represented in figure 16 and the identification of wake region is observed for the wind angle $0^{\circ}, 45^{\circ}$ and $90^{\circ}$.

- The outcome of pressure coefficient $\left(\mathrm{C}_{\mathrm{p}}\right)$ obtained from CFD shows an equal agreement with the experimental values, and no substantial deviation occurs from the results obtained by performing of error analysis using $\mathrm{R}^{2}$, MAE, RMSE and MAPE and the obtained values is within the allowable limits.

- The maximum drag coefficient is obtained in $45^{\circ}$ wind angle is $55.34 \%$ higher than $0^{\circ}$ wind angle drag coefficient and maximum lift coefficient is obtained at $45^{\circ}$ wind angle is $35.7 \%$ higher than $0^{\circ}$ wind angle lift coefficient.

The future scope of this work is to perform the wind flow around irregular plan shape building model under transient condition with different turbulence model and to study the dynamic behaviour of buildings subjected to wind loads.

\section{Acknowledgment}

The author would like to thank Department of Civil Engineering in Mepco Schlenk Engineering College, India and Department of Aeronautical Engineering Kumaraguru Engineering College, India, for providing adequate Computation and Experimental facilities to carry out the research study and sincerer thanks to Institute of Engineers (India) IE(I) for its grateful financial support (Project ID: DR2020004) to complete the project work successfully. 


\section{References}

[1] Yasushi Uematsu., Motohiko Yamada., Akira Inoue., Takeshi Hongo., Wind loads and wind-induced dynamic behavior of a single-layer latticed dome, J. of Wind Eng and Industrial Aerodynamics., 66(3), 227-248, 1997

[2] G, M, Richardson., R, P, Hoxey., A, P, Robertson., J, L, Short., The Silsoe Structures Building: Comparisons of pressures measured at full scale and in two wind tunnels, $\mathrm{J}$ of Wind Eng and Industrial Aerodynamics., 72, 187-197, 1997

[3] Chita Ganapathi, S., Harikrishna, P., Selvi Rajan, S., Effects of upstream terrain characteristics on aerodynamic coefficient of structures, Archives of Civil and Mechanical Engineering., 17(4), 776-785, 2017

[4] Ben Mou., Bao-Jie He., Dong-Xue Zhao., Kwok wing Chau., Numerical simulation of the effects of building dimensional variation on wind pressure distribution, Engineering Application of Computational Fluid Mechanics., 11, 293-309, 2017

[5] Gu, M., Quan, Y., Across-wind loads of typical tall buildings, J of Wind Eng and Industrial Aerodynamics., 92, 1147-1165, 2004

[6] Zhao Liu., Chaorong Zheng., Yue Wu., Richard G.J. Flay., Kan Zhang., Investigation on the effects of twisted wind flow on the wind loads on a square section megatall building, J of Wind Eng and Industrial Aerodynamics., 191, 127-141, 2019

[7] Ashutosh Sharma., Hemant Mittal., Ajay Gairola., Mitigation of wind load on tall building through aerodynamic modifications: Review, J. of Building Eng., 18, 180-194, 2018

[8] Kim Y., Kanda J., Characteristics of aerodynamic forces and pressures on square plan buildings with height variations, J of Wind Eng and Industrial Aerodynamics., 98, 449465,2010

[9] Biswarup Bhattacharyya., Sujit Kumar Dalui., Investigation of mean wind pressure on E plan shaped tall building. Wind and structures., 26(2), 99-114, 2018

[10] Rajdip Paul and Sujit Kumar Dalui, Wind effects on 'Z' plan-shaped tall building: a case study, Int J Adv Struct Eng., 8, 319-335, 2016

[11] W.P. Jones and B.E Launder, The prediction of laminarization with a two equation model of turbulence, Int. Journal of Heat and Mass transfer., 15, 301-314, 1972

[12] Hargreaves, D, M., Wright, N, G., On the use of the k- $\varepsilon$ model in commercial CFD software to model the neutral atmospheric boundary layer, J of Wind Eng. and Industrial Aerodynamics., 95, 355-369, 2007

[13] Franke, J., Hellsten, A Schlunzen, K, H., Carissimo, B., The COST 732 Best practice Gudelines for CFD simulation of flow in urban Environment: A summary, International $\mathrm{J}$ of Environment and Pollution., 44, 419-427, 2011

[14] Tominaga, Y., Mochida, A., Yoshie, R., Kataoka, H., Nozu, T., Yoshikawa M., Shirasawa, T., AIJ guidelines for practical application of CFD to pedestrian wind environment around building, J of Wind Eng. and Industrial Aerodynamics., 96 (1011), 1749-176, 2008 
[15] Peter Sachs., Wind forces in Engineering, 2nd Edition., Pergamon Press., 1978

[16] Rajasekarababu, K., Vinayagamurthy, B., Selvi Rajan. S., Experimental and Computational investigation of outdoor wind flow around a setback building, Building Simulation., 12, 891-904, 2019

[17] Zhao, X., Ding, J.M., Sun, H., Structural Design of Shanghai Tower for wind Loads, Procedia Engineering., 14, 1759-1767, 2011

[18] Suresh Kumar, K., Wind loading on tall buildings: Review of Indian Standards and recommended amendments, J of Wind Eng. and Industrial Aerodynamics., 204, 104240,2020

[19] Hellsten, A., Schunzen, K.H., Carissimo, B., (2007), Best Practice Guidelines for the CFD simulation of flow in the urban Environment, Brussels: COST office.

[20] Y.C Kim, E.K Bandi, A.Yoshida, Y.Tamura, Response characteristics of super tall building - Effect of number of sides and helical angles, J of wind Eng. and Industrial Aerodynamics., 145, 252-262, 2015

[21] Jiming Xie, Aerodynamic optimization of super tall buildings and its effectiveness assessment. J of wind Eng. and Industrial Aerodynamics., 130, 88-98, 2014

[22] Eswara Kumar Bandi, Yukio Tamura, Akihito Yoshida, Yong Chul Kim, Qingshan Yang, Experimental investigation on aerodynamics characteristic of various triangular section high rise buildings., J of Wind Eng. and Industrial Aerodynamics, 122, 60-68, 2013

[23] Hideyuki Tanaka, Yukio Tamura, Kazuo Ohtake, Masayoshi Nakai, Yong Chul Kim, Eswara Kumar Bandi, Aerodynamic and Flow Characteristics of Tall buildings with various Unconventional Configurations, International Journal of High-Rise buildings., 2(3), 213-228, 2013.

[24] Souvik Chakraborty, Sujit Kumar Dalui, Ashok Kumar Ahuja, Wind load on irregular plan shaped tall building - a case study, Wind and Structures., 19 (1), pp. 59-73, 2014.

[25] Prasenjit Sanyal, Sujit Kumar Dalui, Effect of courtyard and opening on a rectangular plan shaped tall building under wind load, International Journal of Advanced Structural Eng., 10, 169-188, 2018

[26] Amin, J.A, Ahuja, A.K., Characteristic of wind forces and responses of rectangular tall buildings, International Journal of Advanced Structural Eng., 6(66), 2018

[27] Monalisa Mallick, Abinash Mohanta, Awadhesh Kumar, Vivek Raj, Modelling of wind pressure coefficient in C-shaped building models, Modelling and simulation in Eng., 6524945,2018 
